\title{
BioFeedback
}

\section{[Letter to the editor] \\ Loss of cationic peptides with agarose gel-immobilized tris[2- carboxyethyl]phosphine (TCEP)}

Trivalent phosphines have been used for disulfide reduction for many years $(1,2)$. Tris[2-carboxyethyl]phosphine (TCEP) has the added advantages of water solubility, broad $\mathrm{pH}$ stability, and minimal reactivity toward other functional groups found in proteins. In contrast to reducing agents such as dithiothreitol, TCEP does not contain thiols, and thus its removal is not required before subsequent modification of reduced proteins and peptides. However, TCEP can react with maleimidyl, iodoacetic acid and iodoacetamide compounds commonly used for protein and peptide modification $(3,4)$. For this reason, agarose gel-immobilized TCEP has been commercially developed (e.g., Pierce, G-Biosciences) to allow immediate use of TCEP-reduced proteins and peptides without requiring gel filtration or dialysis. As gel-immobilized TCEP has been used to minimize TCEP interference, we have applied it to reduction of various proteins with great success. However, when we used this gel to reduce a number of cysteinecontaining cationic peptides, we recently observed a potential side effect of this matrix-namely significant sample loss.
As part of our current research using antimicrobial peptides (AMPs) to capture, detect, and classify various microbial targets (5-10), we have used a number of AMPs with engineered cysteine residues for accurate quantification or to allow oriented immobilization onto surfaces $(9,10)$. For the present study, a series of eight custom peptides based on the cationic AMPs cecropin A (KWKLFKKIEKVGQNIRDGIIKAGPAVAVVGQATQIAK), cecropin B (KWKVFKKIEKMGRNIRNGIVKAGPAIAVLGEAKAL), melittin (GIGAVLKVLTTGLPALISWIKRKRQQ), and

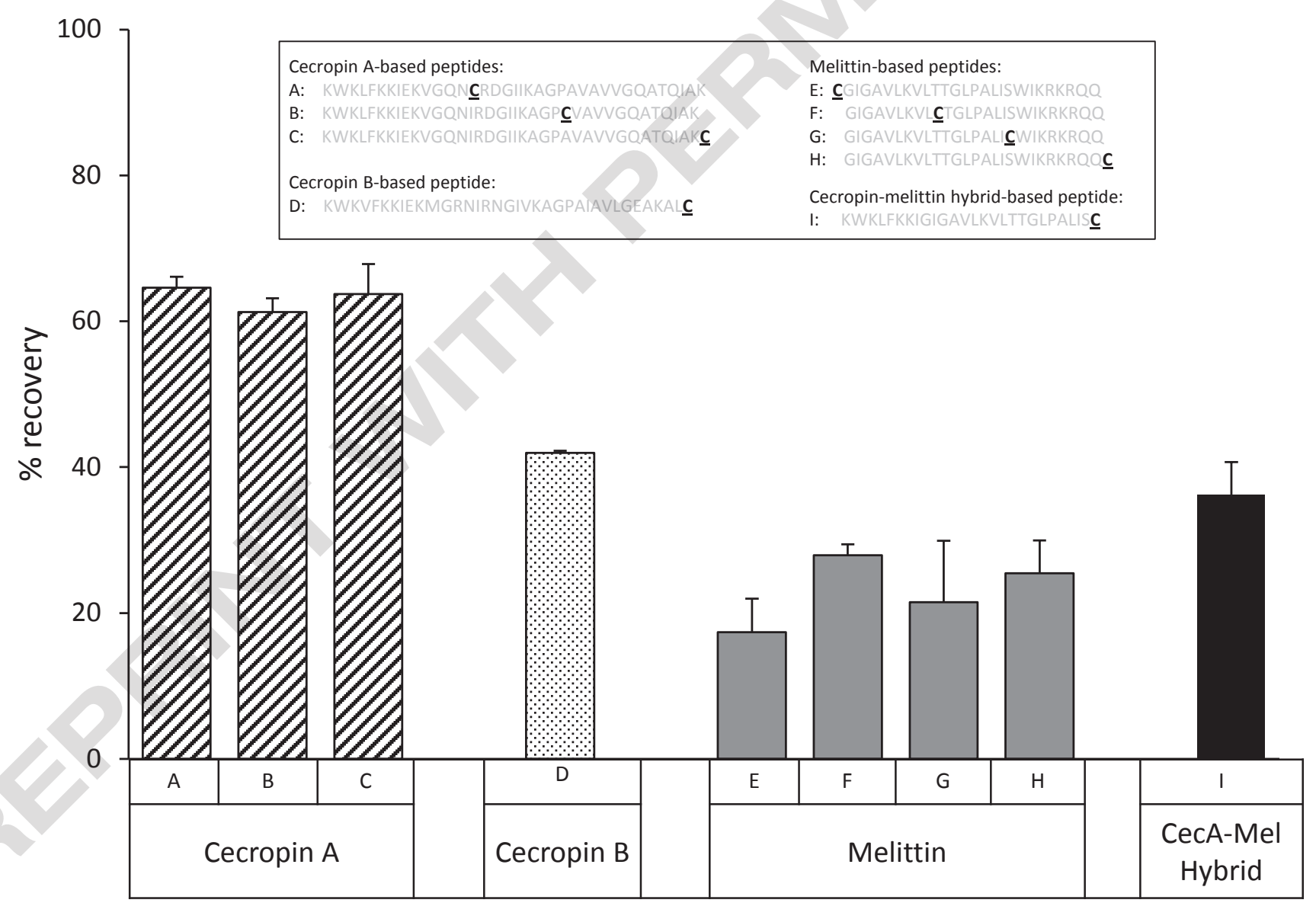

Figure 1. Recovery of cysteine-containing peptides after treatment with immobilized TCEP gel. Construct sequences are shown above the graph with sequences of the base peptides shown in gray: cecropin A (constructs A-C, striped bars), cecropin B (construct D, stippled bar), melittin (constructs E-H, gray bars), and cecropin A (1-8)-melittin (1-18) hybrid peptide (construct I, black bar). The position of the unique cysteine in each construct is indicated as the underlined residue. 
cecropin A (1-8)-melittin (1-18) hybrid peptide (KWKLFKKIGIGAVLKVLTTGLPALIS) were synthesized to possess a unique cysteine at various loci without changing the peptides' net charge ( $90 \%$ purity, Biosynthesis, Inc. Lewisville, TX)(Figure 1). Each peptide was diluted to $0.7-1.0 \mu \mathrm{g} / \mathrm{mL}$ in phosphate-buffered saline (PBS), pH 7.4 and then treated with $5 \mathrm{mM}$ neutralized TCEP or $100 \mu \mathrm{L}$ immobilized-TCEP (catalog \# 20490 and 77712, respectively; Pierce, Rockford, IL) for $20 \mathrm{~min}$ to ensure complete reduction of any dithiols. Given TCEP's instability in phosphate buffers (11), TCEP gel and TCEP stock solutions were made up immediately prior to use. After treatment, the agarose gel was removed from peptides by centrifugation and/or filtration. Peptide concentrations of TCEP- and TCEP-agarose-treated solutions were determined by absorbance at $280 \mathrm{~nm}$ (Thermo Scientific NanoDrop 2000, Thermo Scientific, Waltham, MA USA, cat no. ND-2000). Each sample was prepared in triplicate. Sepharose 4B (agarose gel, catalog \# 17-0120-01; GE Healthcare, Piscataway, NJ) was used as a control to determine the extent of loss (if any) attributable to the agarose matrix itself.

As expected, treatment of peptides with 5 mM TCEP solution or buffer (no TCEP) resulted in no significant peptide loss or precipitation when compared with untreated controls $(P>0.15)$. Small but statistically significant losses $(3 \%-15 \%)$ were incurred when treating peptides with Sepharose $(P<$ 0.005); similar losses have been observed with protein controls (data not shown). However, significantly greater losses were observed when peptides were treated with agarose gel functionalized with TCEP $(P<0.00001$; Figure 1).

The degree of loss on the gel-immobilized TCEP appeared to be peptide-specific for the four base peptides tested. The highest losses (up to $85 \%$ ) were observed with the 4 different melittin constructs, independent of the locations of the cysteinyl residues, whereas 35\%-40\% losses were observed with analogous cecropin A constructs. Losses intermediate between those for these two peptides were observed with a hybrid peptide comprising domains from melittin and cecropin. Interestingly, the degree of loss could not be directly related to the net charge at neutral $\mathrm{pH}$, mean hydrophobicity, mean or relative hydrophobic moments, or position of the unique cysteinyl residues.

In spite of the lack of direct relationship between losses and net peptide charge, we anticipated that there might be an interaction between the cationic peptides and immobilized TCEP, which displays one or more carboxyl moieties. We therefore incubated the series of cysteinyl peptides, demonstrating the highest losses with immobilized TCEP gel under conditions of varying ionic strengths (10 $\mathrm{mM}$ phosphate buffer with $0.15 \mathrm{MNaCl}$ [PBS] to $1 \mathrm{MNaCl}$, final $\mathrm{pH}=7.4$ ) (Figure 2). While recoveries of 2 constructs were improved by increasing the ionic strength to $>0.3 \mathrm{M}$, inclusion of $1 \mathrm{M} \mathrm{NaCl}$ significantly improved peptide recovery for all 4 peptides tested $(P<$ $0.05)$. Thus, peptide losses due to electrostatic interactions could be partially (constructs $\mathrm{E}$ and $\mathrm{H}$ ) or fully (constructs $\mathrm{F}$ and $\mathrm{G}$ ) mitigated by use of higher ionic strength buffers.

The utility of a one-pot reaction for both reduction and labeling of protein and peptide thiols - with minimal manipulation required to remove TCEP - is appealing, and high-efficiency labeling of proteins following treatment with immobilized TCEP can be accomplished (12). In our hands, however, significantly greater losses of cationic peptides were observed after treatment with agaroseimmobilized TCEP than with naked agarose. While this loss could be mitigated with higher ionic strength buffers, the full extent of recovery still depended on the peptide used; even in the presence of $1 \mathrm{M} \mathrm{NaCl}$,

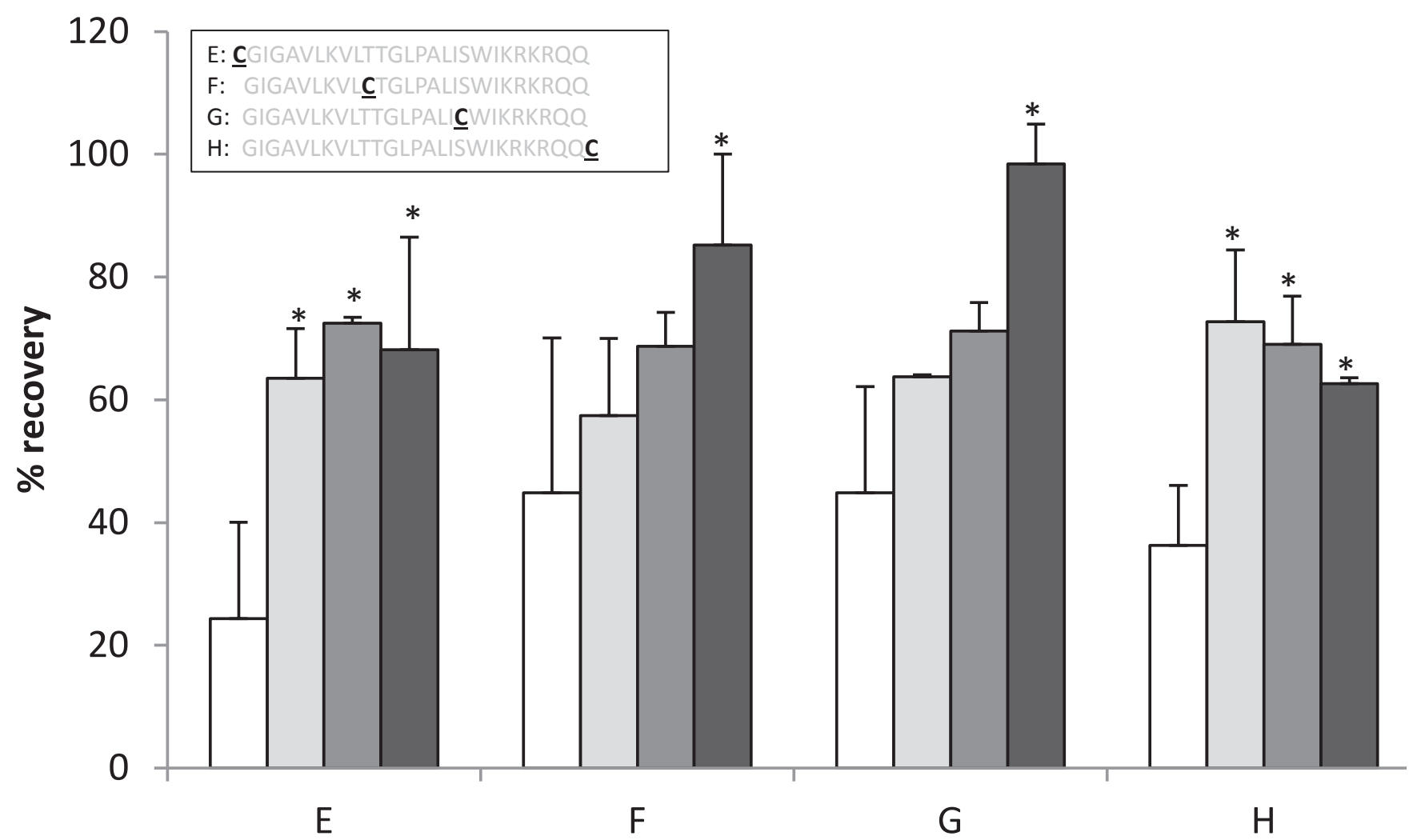

Figure 2. Recovery of cysteine-containing melittin constructs. Constructs were incubated with immobilized TCEP gel in phosphate buffer containing $0.15 \mathrm{M}$ NaCl (PBS, white), $0.3 \mathrm{M} \mathrm{NaCl}$ (light gray), $0.5 \mathrm{M} \mathrm{NaCl}$ (medium gray), or $1 \mathrm{M} \mathrm{NaCl}$ (dark gray). Construct sequences are shown above the graph with sequences of the base peptide (melittin) shown in gray. The positions of the unique cysteines are indicated as the underlined residue. Asterisks above the bars indicate a significant $(P<0.05)$ improvement over recoveries obtained with PBS. 


\section{BioTechniques}

Wonthly

Issues Now

Avaiflable

for ipad and

fphone in

the fromes

App Store

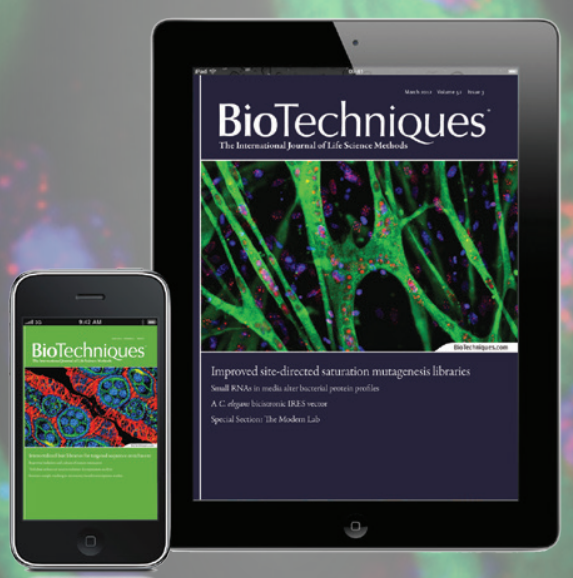

Scan the QR Code or visit the App Store and search for "BioTechniques" to download. some peptides were still not recovered at levels approaching $100 \%$.

Our results emphasize a potential pitfall associated with use of immobilized TCEPreagents, namely sample loss during reduction. Our observations additionally highlight the need to quantify peptides after treatment with these matrices. While a 37\%-56\% decrease in peptide immobilization on maleimideactivated surfaces was observed if soluble TCEP was not removed (determined by far-UV circular dichroism spectroscopy; data not shown) (13), losses of similar magnitude were observed with samples that were reduced with immobilized TCEP. In some cases, these losses could be only partially recovered by high salt concentrations. This trade-off should be carefully considered when samples are precious, low ionic strength is needed, or purification of reduced species after TCEP treatment is not feasible.

\section{Author contributions}

L.C.S.-L. performed the reductions, quantified the peptides, analyzed the data, and edited the manuscript. S.H.N. contributed to conception, design of the experiments, analyzed the data, performed immobilization experiments (efficiency of covalent modification after treatment), and edited the manuscript. C.R.T conceived and designed the experiments, performed controls, analyzed the data (statistics), and prepared the manuscript

\section{Acknowledgments}

This work was supported by the Office of Naval Research and the Naval Research Laboratory. The opinions expressed herein are those of the authors and do not reflect those of Office of Naval Research, the Naval Research Laboratory, the US Navy or Department of Defense, or the US Government.

\section{Competing interests}

The authors declare no competing interests.

\section{References}

new approach to protein PEGylation. Bioconjug. Chem. 22:132-136.

5. Kulagina, N., C. Taitt, G. P. Anderson, and F. S. Ligler. Affinity-based detection of biological targets. Allowed US Patent Appl. Pub. No. 2006/0281074.

6. Kulagina, N.V., M.E. Lassman, F.S. Ligler, and C.R. Taitt. 2005. Antimicrobial peptides for detection of bacteria in biosensor assays. Anal. Chem. 77:6504-6508.

7. Kulagina, N.V., K.M. Shaffer, G.P. Anderson, F.S. Ligler, and C.R. Taitt. 2006. Antimicrobial peptide-based array for Escherichia coli and Salmonella screening. Anal. Chim. Acta 575:9-15.

8. Kulagina, N.V., K.M. Shaffer, F.S. Ligler, and C.R. Taitt. 2007. Antimicrobial peptides as new recognition molecules for screening challenging species. Sens. Actuators B Chem. 121:150-157.

9. North, S.H., J. Wojciechowski, V.M. Chu, and C.R. Taitt. 2012. Surface immobilization chemistry influences peptide-based detection of lipopolysaccharide and lipoteichoic acid. J. Pept. Sci. 18:366-372.

10. Shriver-Lake, L.C., S.H. North, S.N. Dean, and C.R. Taitt. 2013. Antimicrobial peptides for detection and diagnostic assays, p. 85-104. In S A. Piletsky and M.J. Whitcomb (ed.), Designing receptors for the next generation of biosensors. Springer, Heidelberg.

11. Han, J.C. and G. Han. 1994. A procedure for quantitative determination of tris(2-carboxyethyl)phosphine, an odorless reducing agent more stable and effective than dithiothreitol. Anal. Biochem. 220:5-10.

12. Tzanavaras, P.D., C. Mitani, A. Anthemidis, and D.G. Themelis. 2012. On-line cleavage of disulfide bonds by soluble and immobilized tris(2-carboxyethyl)phosphine using sequential injection analysis. Talanta 96:21-25.

13. Fears, K.P. and R. Latour. 2009. Assessing the influence of adsorbed-state conformation on the bioactivity of adsorbed enzyme layers. Langmuir 25:13926-13933.

Received 04September 2013; accepted 01 November, 2013.

Lisa C. Shriver-Lake, Stella H. North, and Chris Rowe Taitt

Center for Bio/Molecular Science \& Engineering, US Naval Research Laboratory, Washington, DC

BioTechniques 55:292-294 (December 2013) doi 10.2144/000114112

Keywords: Tris[2-carboxyethyl]phosphine; TCEP; peptide/protein reduction; immobilized TCEP; antimicrobial peptide sides. 1991. Selective reduction of disulfides by tris(2-carboxyethyl)phosphine. J. Org. Chem. 56:2648-2650.

2. Levison, M.E., A.S. Josephson, and D.M. Kirschenbaum. 1969. Reduction of biological substances by water-soluble phosphines: Gamma-globulin (IgG). Experientia 25:126-127.

3. Shafer, D.E., J.K. Inman, and A. Lees. 2000. Reaction of tris(2-carboxyethyl)phosphine (TCEP) with maleimide and $\alpha$-haloacyl groups: Anomalous elution of TCEP by gel filtration. Anal. Biochem. 282:161-164.

4. Schumacher, F.F., M. Nobles, C. Ryan, M. Smith, A. Tinker, S. Caddick, and J. Baker. 2011. In situ maleimide bridging of disulfides and a
Address correspondence to Chris Rowe Taitt, Center for Bio/Molecular Science \& Engineering, US Naval Research Laboratory, Washington, DC. E-mail: chris.taitt@nrl.navy.mil

To purchase reprints of this article, contact: biotechniques@fosterprinting.com 